\title{
Kinetics and Thermodynamics of Poly(9,9-dioctylfluorene) $\beta$-Phase Formation in Dilute Solution
}

\author{
Fernando B. Dias, ${ }^{*}, \dagger$ Jorge Morgado, $,+, \S, \|$ António L. Maçanita, $*, \dagger$ \\ Fernando P. da Costa, ${ }^{\perp}$ Hugh D. Burrows, ${ }^{\#}$ and Andrew P. Monkman
}

\begin{abstract}
Departamento de Engenharia Química e Biológica, Centro de Química Estrutural, Instituto Superior Técnico, Avenida Rovisco Pais, P-1049-001 Lisboa, Portugal; Department of Physics, University of Durham, Durham DH1 3LE, UK, Departamento de Engenharia Química e Biológica, Instituto Superior Técnico, Avenida Rovisco Pais, P-1049-001 Lisboa, Portugal; Instituto de Telecomunicações, Avenida Rovisco Pais, P-1049-001 Lisboa, Portugal; Universidade Aberta, Lisboa, Portugal, and CAMGSD, Instituto Superior Técnico, Lisboa, Portugal; and Departamento de Química, Universidade de Coimbra, P-3004-535 Coimbra, Portugal
\end{abstract}

Received February 8, 2006; Revised Manuscript Received June 26, 2006

\begin{abstract}
Poly(9,9-dioctylfluorene) (PFO) adopts a particular type of conformation in dilute solutions of the poor solvent methylcyclohexane $(\mathrm{MCH})$ below $273 \mathrm{~K}$, which is revealed by the appearance of a red-shifted absorption peak at $437-438 \mathrm{~nm}$. The formation of this ordered conformation depends on the temperature but is independent of polymer concentration over the range studied $(3-25 \mu \mathrm{g} / \mathrm{mL})$. On the basis of absorption, steadystate, and time-resolved fluorescence data, the new absorption peak at $437-438 \mathrm{~nm}$ is assigned to a highly ordered conformation of PFO chains, analogous to the so-called $\beta$-phase first identified in PFO films. From the study of $\mathrm{PFO}$ solutions in $\mathrm{MCH}$ as a function of temperature, we conclude that these ordered segments ( $\beta$-conformation) coexist with less ordered domains in the same chain. When the ordered domains are present, they act as efficient energy traps and the fluorescence from the disordered regions is quenched. The transition between the disordered and the ordered PFO conformations is adequately described by a mechanism that involves two steps: a first, essentially intramolecular, one from a relatively disordered $(\alpha)$ to an ordered conformation $(\beta)$, followed by aggregation of chains containing $\beta$-conformation into anisotropic ordered domains. From the temperature dependence of the 437-438 nm peak intensity, the transition temperature $T_{\beta}=261 \mathrm{~K}$, enthalpy $\Delta H_{\beta}=-18.0$ kcal mol ${ }^{-1}$, and entropy $\Delta S_{\beta}=-68.4 \mathrm{cal} \mathrm{K}^{-1} \mathrm{~mol}^{-1}$ were obtained. The formation of the $\beta$-conformation domains were also followed as a function of time at $260 \mathrm{~K}$. The rate constants at $260 \mathrm{~K}$ were determined, showing an order of magnitude around $10^{-3} \mathrm{~s}^{-1}\left(k_{\alpha \rightarrow \beta}=5.9 \times 10^{-4} \mathrm{~s}^{-1} ; k_{\beta \rightarrow \alpha}=9 \times 10^{-4} \mathrm{~s}^{-1} ; k_{\mathrm{agg}}=2.3 \times 10^{-3} \mathrm{M}^{-1} \mathrm{~s}^{-1}\right.$; $k_{\text {diss }}=4.4 \times 10^{-4} \mathrm{~s}^{-1}$ ). This small magnitude explains the long times required for a "complete" conversion to the $\beta$-conformation.
\end{abstract}

\section{Introduction}

Thermochromic and solvatochromic effects on films and solutions of conjugated polymers, such as poly(9,9-dioctylfluorene) (PFO) and related copolymers, have been widely discussed in the literature in the past few years. ${ }^{1-4}$ Two main entities have been invoked to interpret these spectral changes: (i) interchain states, resulting from interactions between different chains or between sufficiently spaced segments of a same long polymer chain, and (ii) conformationally ordered chain segments, such as the extended $\beta$-phase first identified in solid PFO. The relevance of interchain states, such as aggregates and excimers, on the photophysics of electroluminescent polymers, in general, and of polyfluorenes, PFs, in particular, has attracted much attention. This interest derives not only from the need of understanding the fundamental properties of PFs but also from its relevance for their applications, particularly in light-emitting devices. For example, the observation of a contaminant greenish

\footnotetext{
† Centro de Química Estrutural, Instituto Superior Técnico.

University of Durham.

$\S$ Departamento de Engenharia Química e Biológica, Instituto Superior Técnico.

"Instituto de Telecomunicações.

${ }^{\perp}$ Universidade Aberta.

\# Universidade de Coimbra.

* To whom correspondence should be addressed. E-mail fmbdias@ durham.ac.uk,jmorgado@gcsi.ist.utl.pt,macanita@ist.utl.pt.
}

emission above $500 \mathrm{~nm}$ from blue-emitting PFs was initially attributed to interchain emissive states, though experimental evidence has recently been gathered supporting the existence of fluorenone defects (photooxidized repeat units) as an alternative source of such emission. ${ }^{5}$ In PFs having short, linear side groups, such as poly(9,9-dihexylfluorene), $\mathrm{PFH}$, where interchain $\pi-\pi$ interactions in ground or excited states are facilitated, it has been suggested that both phenomena may contribute to this broad nonstructured greenish band. ${ }^{6,7}$

The so-called $\beta$-phase of PFO was originally reported by Bradley et al. ${ }^{2,3,8}$ in 1997 , who reported the appearance of a shoulder close to the onset of the absorption band of films of both neat PFO, PFO dispersed in polystyrene, and PFO solutions in poor solvents (such as cyclohexane). This shoulder could, upon appropriate treatment, evolve into a well-defined peak with a maximum at $437 \mathrm{~nm}$. In particular, it was observed that this peak becomes more prominent in films exposed to solvents or upon their slow warming from $77 \mathrm{~K}$ up to room temperature. On the basis of fiber X-ray diffraction studies, Bradley et al. ${ }^{8}$ concluded that this lower energy state is associated with particularly extended conformations of PFO chains, ${ }^{8,9}$ resulting from the polymer response to some physical stress, driven by solvent quality or temperature. ${ }^{3,4,8} \mathrm{In}$ another study, Teetsov et al. ${ }^{7,10}$ reported that the $437 \mathrm{~nm}$ absorption band is also formed with dihexyl- and didodecyl-substituted polyfluorenes and attributed the phenomenon to polymer aggregation. 
The scientific interest focused on this $\beta$-phase peak in PFO films is revealed by a significant number of publications devoted to its study, using in particular time-resolved spectroscopies. ${ }^{11-15}$ In contrast, studies on characterization of the corresponding PFO ordered state in solution are still scarce. Since the first indication by Bradley et al., ${ }^{2}$ other reports have shown a correlation between the intensity of this red-shifted peak and the poorsolvent content in solutions of good-solvent/poor-solvent mixtures (chloroform/methanol). ${ }^{4,16}$ Furthermore, it has been suggested that octyl side chains in PFO are particularly effective at inducing and stabilizing such intramolecular ordering in solution, when compared to hexyl and dodecyl side groups. . $^{70}$ The concept of side chain-driven planarization upon polymer agglomeration in solvent mixtures due to an increase of the fraction of a poor-solvent was also introduced. ${ }^{16}$ More recently, the conformations of (isolated) PFO chains were addressed by means of theoretical calculations. Chunwaschirasiri et al. ${ }^{17}$ have found three different isomers: (i) $\alpha$, corresponding to a more disordered and twisted structure, which they relate to the glassy phase of solid-state PFO; (ii) a second isomer $(\gamma)$ related to samples heated to $430 \mathrm{~K}$; and (iii) the $\beta$-isomer, for which they found a single chain conformation, with a torsion angle of about $165^{\circ}$ (more flat conformation). They also propose that this $\beta$-conformation is stabilized by the van der Waals interactions between the octyl side chains and the fluorene backbone. According to this model, the stabilization of this conformation does not require interchain interactions, having instead an intrachain nature. Although the calculations involve gas-phase parameters and assume isolated chains and so do not take into account solvent interactions, this is an attractive model and can explain the observed spectroscopic properties, providing an explanation for the specificity of the linear octyl chain for inducing these effects.

However, the nature of the process leading to the $\beta$-phase formation in dilute solutions of PFO, in particular, the distinction between intra- vs intermolecular nature of the process, still remains a matter of debate and has been a source of different interpretations. ${ }^{8-10}$ In fact, the $437 \mathrm{~nm}$ absorption peak also appears when PFO is not completely dissolved, being associated with special aggregates (visible under UV light illumination and which can be removed upon filtration) present in the solid sample, which are formed during the PFO purification by addition of a poor solvent or during the solvent removal. In addition, PFO is a member of the group of so-called "hairyrod" polymers, which have a tendency to exist as supramolecular aggregates, even at very low concentrations. ${ }^{18}$ Steric requirements in these systems mean that we must maintain a relatively rigid polyfluorene backbone, while trying to maximize alkyl chain association via various through-space interactions (mainly van der Waals type), with either polymer or solvent, at the expense of intermolecular alkyl-aryl interactions. We, therefore, cannot rule out the possibility that PFO already exists as a dimeric or oligomeric aggregate under the conditions studied. However, the lack of effect on emission and absorption spectra shows that these do not involve intermolecular interactions between polyfluorene backbones.

In this work, we present the optical characterization of the $\beta$-phase at room temperature and, in particular, a study of very dilute solutions of PFO in methylcyclohexane (MCH), in which we induced the appearance of an ordered state upon cooling. We present the spectral features of PFO ordered domains $(\beta$ conformation, which, by similarity with the solid state, we also name $\beta$-phase) and compare the optical properties with those of poly[9,9-bis(2'-ethylhexyl)fluorene] (PF2/6) and of a ladder-
Chart 1. Molecular Structures of PFO, PF2/6, and MeLPPP
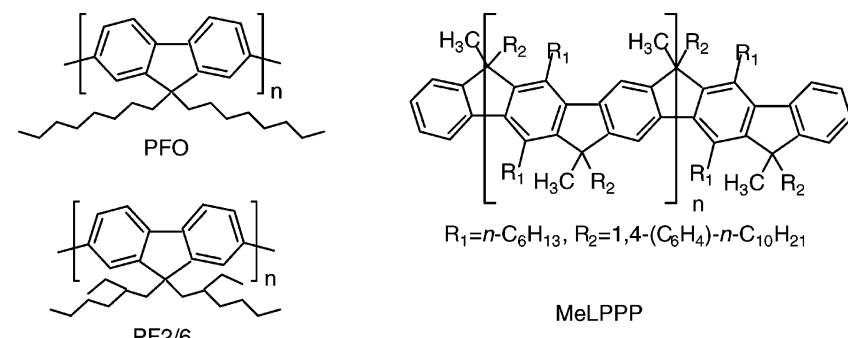

$\mathrm{R}_{1}=n-\mathrm{C}_{6} \mathrm{H}_{13}, \mathrm{R}_{2}=1,4-\left(\mathrm{C}_{6} \mathrm{H}_{4}\right)-n-\mathrm{C}_{10} \mathrm{H}_{21}$

MeLPPP

type poly( $p$-phenylene), MeLPPP (see Chart 1$)$. We finally provide kinetic evidence showing that the adoption of the more extended conformation revealed by the presence of the redshifted absorption peak at $437 \mathrm{~nm}$, possible with PFO but not with PF2/6, involves a two-step process: a first, essentially intramolecular one followed by aggregation.

\section{Experimental Section}

2.1. Compounds and Sample Preparation. $P F O$ has molecular weight $M_{\mathrm{n}}=1.88 \times 10^{5}$ and $M_{\mathrm{w}}=3.31 \times 10^{5}$, with respect to polystyrene standards. PF2/6 samples, with molecular weight $M_{\mathrm{n}}=9.15 \times 10^{4}$ and $M_{\mathrm{w}}=1.9 \times 10^{5}$, were prepared by Yamamoto coupling ${ }^{19}$ as described elsewhere. ${ }^{20}$ The absence of fluorescent impurities in the polymer samples was further confirmed by timeresolved fluorescence data. The most common impurity of polyfluorenes results from photooxidation of fluorene at the 9-position (most probably at defect monosubstituted sites) to give a fluorenone unit. ${ }^{5}$ The fluorenone impurity reveals itself by a broad emission above $500 \mathrm{~nm}$, which was not observed in pristine films of our polymer samples. The synthesis, purification, and properties of MeLPPP were previously reported. ${ }^{21-23}$ The polymer has a molecular weight $M_{\mathrm{n}} \approx 6.9 \times 10^{4}$ and a polydispersity of ca. 2.8 . Methylcyclohexane (MCH) and tetrahydrofuran (THF) were purchased from Romil and used as received.

To prepare clear solutions of PFO, it is necessary to warm the solutions under stirring. The temperature required to achieve a fully dissolved material depends on the solvent and on concentration. To prepare clear solutions of PFO in $\mathrm{MCH}$ or cyclohexane $(\mathrm{CH})$ in the concentration range of $1-25 \mu \mathrm{g} / \mathrm{mL}$, it was necessary to take the solution at $363 \mathrm{~K}$ under magnetic stirring for $30 \mathrm{~min}$. Solutions prepared at $343 \mathrm{~K}$, or below, and left to equilibrate at room temperature in the dark present a red-shifted absorption peak at $437-438 \mathrm{~nm}$, but solutions prepared at $363 \mathrm{~K}$ do not present that red-shifted peak after the equilibrium at room temperature is achieved. In this case, the red-shifted absorption peak can be recovered by cooling the solutions to $270 \mathrm{~K}$.

Concentrations in the range of $3-25 \mu \mathrm{g} / \mathrm{mL}$ were used in this work. Solutions whose concentration is not specified in the text always had absorbance values close to 0.1 (corresponding to about $3 \mu \mathrm{g} / \mathrm{mL})$ at the excitation wavelength $(380 \mathrm{~nm})$. The low absorbance of these samples prevents errors in the fluorescence spectra due to self-absorption or the inner filter effect.

2.2. Measurements. UV absorption spectra were recorded with Olis-15 and Perkin-Elmer Lambda 19 spectrophotometers. Fluorescence emission and excitation spectra were recorded using SPEX Fluorolog 2 and Fluoromax 3 spectrofluorimeters. Spectra as a function of temperature were collected using a cryostat model VNF100 from JANIS Research Inc.

Anisotropy measurements were carried out using Glen-Thompson polarizers in the excitation and emission ports of a SPEX Fluorolog 2 with right angle configuration.

Fluorescence decays were measured using picosecond timecorrelated single-photon counting (TCSPC), as described previously. ${ }^{24}$ The excitation source consists of a frequency-doubled Ti: sapphire picosecond laser system (Spectra Physics Inc.), pumped by a $\mathrm{Ar}^{+}$or a Millennia X (Spectra Physics Inc.), repetition rate 4 $\mathrm{MHz}, \mathrm{fwhm}=38 \mathrm{ps}$. Temperature control was achieved using a home-built system as described elsewhere..$^{25}$ Alternate collection 


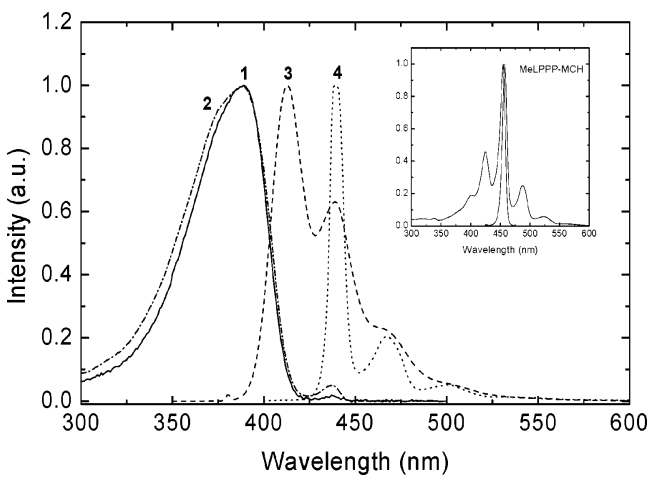

Figure 1. Normalized absorption (curve 1), excitation (with reading at $468 \mathrm{~nm}$, curve 2) and emission spectra with excitation at 380 and $438 \mathrm{~nm}$ (curves 3 and 4 , respectively) of PFO in $\mathrm{MCH}(3 \mu \mathrm{g} / \mathrm{mL})$. The inset shows absorption and emission spectra of the ladder-type polymer, MeLPPP, in MCH.

of pulse and sample signals $\left(10^{3}\right.$ counts at the maximum per cycle) was performed until $5 \times 10^{3}$ counts at the maximum were acquired. The fluorescence decays were deconvoluted in a PC, using the UNIX version of George Striker's program. ${ }^{26}$

\section{Results}

3.1. Optical Properties at Room Temperature. Solutions of PFO in THF, toluene, MCH, or cyclohexane show a broad absorption spectrum in the $300-425 \mathrm{~nm}$ spectral range, with a maximum around $380-390 \mathrm{~nm}$. Heating up to $\sim 333 \mathrm{~K}$, in the case of THF, or up to $363 \mathrm{~K}$, for MCH solutions, is necessary to fully dissolve the material. Cooling down the solutions back to room temperature does not induce any change of the absorption spectra. If PFO is added to THF or $\mathrm{MCH}$, and left stirring (up to several hours) at temperatures below the abovementioned values, an additional absorption peak at 437-438 $\mathrm{nm}$ is observed. Figure 1 shows absorption, excitation, and emission spectra of a PFO dilute solution $(3 \mu \mathrm{g} / \mathrm{mL})$ in $\mathrm{MCH}$ prepared at $343 \mathrm{~K}$, where the red-shifted absorption peak at 437 $\mathrm{nm}$ is clearly visible.

The emission spectrum, obtained with excitation at $380 \mathrm{~nm}$ (curve 3 in Figure 1), is clearly different from that obtained with excitation at $438 \mathrm{~nm}$ (curve 4). Specifically, the emission spectrum obtained upon excitation at $438 \mathrm{~nm}$ exhibits an unusually well-defined vibronic progression with peaks at 440 $\mathrm{nm}(2.82 \mathrm{eV}), 467-468 \mathrm{~nm}(2.65 \mathrm{eV})$, and $500 \mathrm{~nm}(2.48 \mathrm{eV})$.

As previously pointed out, ${ }^{11}$ this emission spectrum is similar to that of the rigid and nearly planar ladder-type polymer MeLPPP in MCH solution (inset of Figure 1) apart from the $18 \mathrm{~nm}(0.11 \mathrm{eV})$ shift. The same vibronic spacing, of about $0.17 \mathrm{eV}$ and a small Stokes shift, is observed in the two emission spectra. In contrast, the emission spectrum of PFO observed upon $380 \mathrm{~nm}$ excitation is much broader and shows a larger spectral shift with respect to the absorption spectrum. The 437 $\mathrm{nm}$ peak is not observed in solutions of the branched side chain polymer $\mathrm{PF} 2 / 6$ in $\mathrm{MCH}$, even when a very high optical density solution $\left(\mathrm{OD}_{\max }=1.88\right)$ is used or when spectra are measured in other solvents ${ }^{27}$ (toluene, decalin, tetrahydrofuran, cyclohexane) or even in films.

If the PFO "solutions" showing the $437 \mathrm{~nm}$ peak are left standing in the dark at room temperature, the intensity of this peak does not decrease. Material in suspension is clearly visible in these "solutions" under illumination with an UV lamp. Furthermore, if these "solutions" are filtered through $0.22 \mu \mathrm{m}$ membranes, the intensity of this peak is strongly suppressed, nearly disappearing.
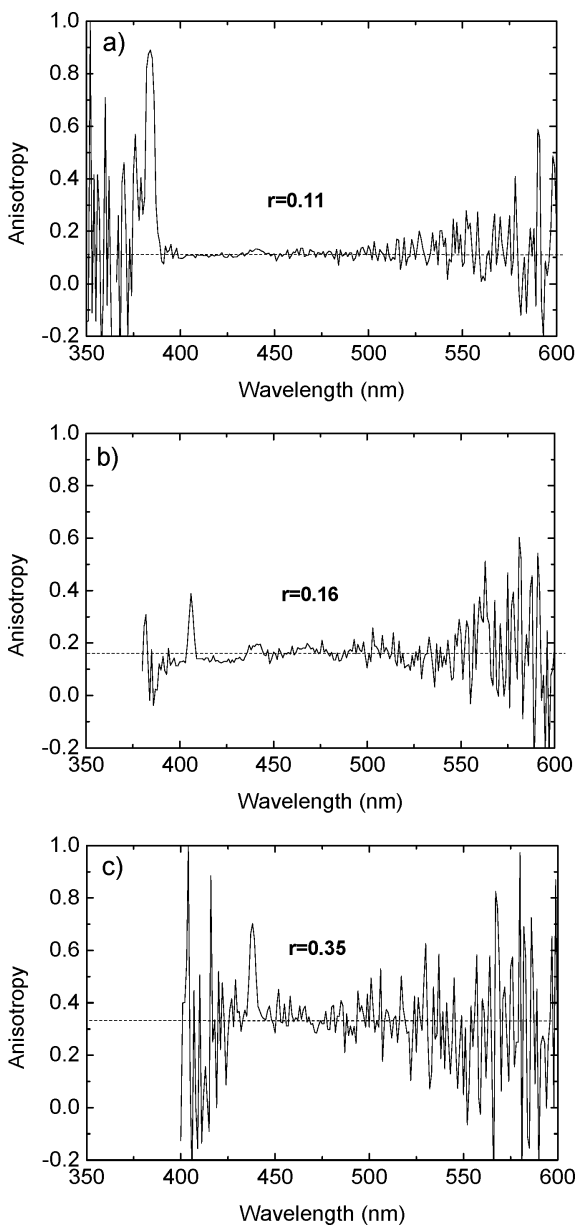

Figure 2. Steady-state fluorescence anisotropy $(\bar{r})$ of $\mathrm{PFO}$ in $\mathrm{MCH}$ solution at $293 \mathrm{~K}$, with excitation wavelength at (a) 384, (b) 406, and (c) $438 \mathrm{~nm}$. The anisotropy value at the red edge $(\bar{r}=0.16)$ is higher than the one at the absorption maximum at $384 \mathrm{~nm}(\bar{r}=0.11)$. The anisotropy value obtained with excitation at the red-shifted absorption peak $(\bar{r}=0.35)$ is close to the theoretical maximum anisotropy value.

Steady-state fluorescence anisotropy studies were carried out for PFO solutions in MCH showing the $437 \mathrm{~nm}$ peak. Figure 2 shows steady-state emission anisotropy data $(\bar{r})$ obtained at room temperature with a $\mathrm{MCH}$ solution of PFO prepared at $343 \mathrm{~K}$ (with the $437 \mathrm{~nm}$ peak), at three different excitation wavelengths: $\lambda_{\mathrm{exc}}=384 \mathrm{~nm}$ (maximum of the main broad band), $\lambda_{\mathrm{exc}}=406 \mathrm{~nm}$ (onset of the main band), and $\lambda_{\mathrm{exc}}=438 \mathrm{~nm}$ (red-shifted peak). We observe that by excitation of PFO near the main absorption red edge (406 $\mathrm{nm}$ ) the anisotropy value $(\bar{r}=0.16)$ is higher than that obtained for the PFO fluorescence when it is excited at the absorption maximum at $384 \mathrm{~nm}(\bar{r}=$ $0.11)$. Even more interesting is the anisotropy value obtained with excitation at the red-shifted absorption peak $(\bar{r}=0.35)$, which is close to the theoretical maximum value.

Time-resolved fluorescence decays of a $\mathrm{PFO} / \mathrm{MCH}$ solution exhibiting the $437 \mathrm{~nm}$ absorption peak were collected at $293 \mathrm{~K}$ by exciting at $372 \mathrm{~nm}$ (within the main absorption band) and collecting the emission at both the onset $(400 \mathrm{~nm})$ and the tail $(468 \mathrm{~nm})$ of the emission band. Global analysis of the two decays shows that sums of three exponentials, with decay times of 15,71 , and $340 \mathrm{ps}$, have to be used to fit them in both cases (Figure 3a). The slow component of 340 ps appears as a decay time (positive amplitude) at both wavelengths and is the main component in the decay; the intermediate component shows residual importance at both wavelengths. However, the fast component of 15 ps appears as a decay time when the emission is collected at the emission onset $(400 \mathrm{~nm})$ and as a rise time 

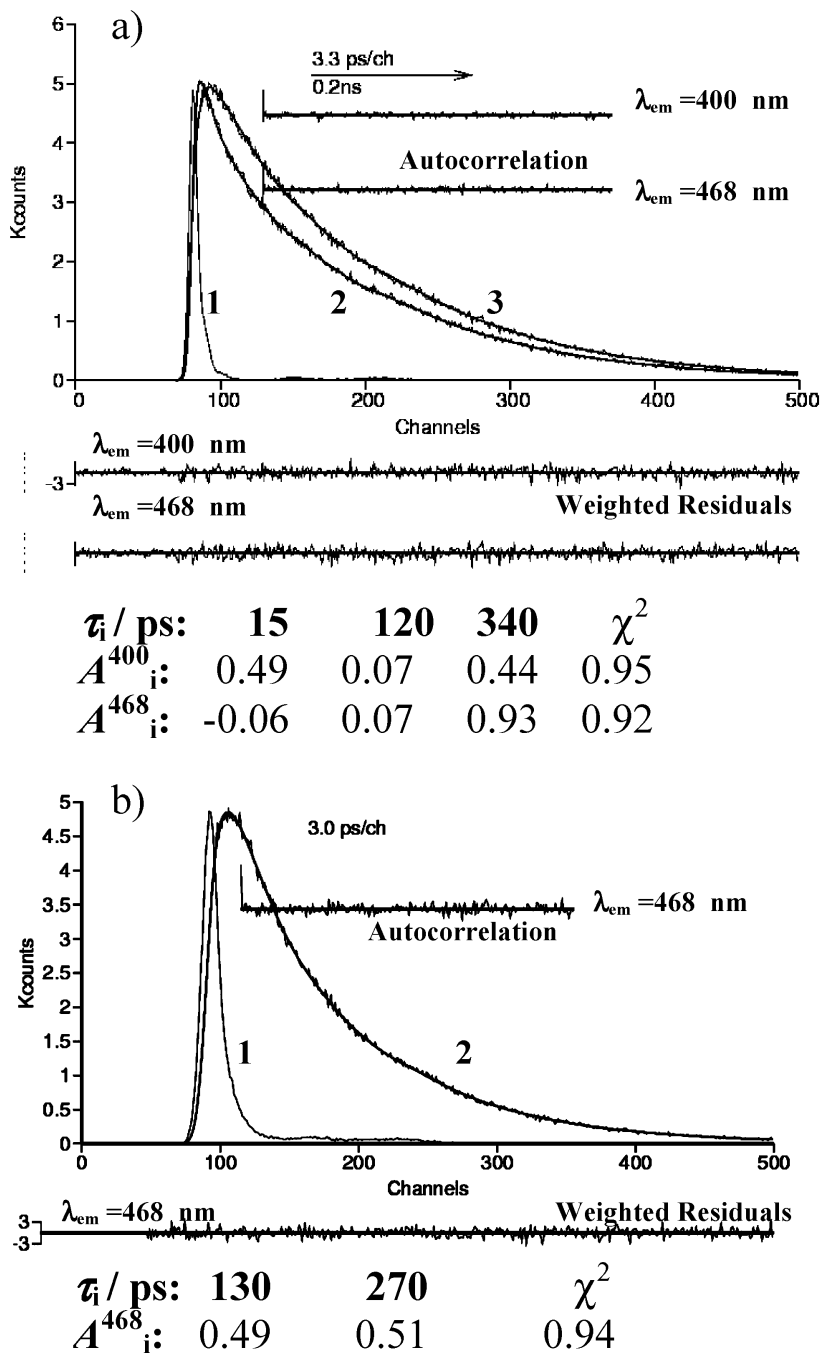

Figure 3. Fluorescence decays of $\mathrm{PFO}$ in $\mathrm{MCH}$ at $293 \mathrm{~K}$. (a) Excitation at $384 \mathrm{~nm}$ (curve 1) and emission at the onset (400 nm, curve 2) and tail ( $468 \mathrm{~nm}$, curve 3 ) of the normal emission band. The global analysis of two decays with three-exponential functions reveals a 15 ps rise time (negative preexponential coefficient) at $468 \mathrm{~nm}$. (b) Excitation at $437 \mathrm{~nm}$ (curve 1) and emission at $468 \mathrm{~nm}$ (curve 2). The doubleexponential fit provides shorter decay times and no rise time.

at lower energies $(\lambda>410 \mathrm{~nm})$. A similar behavior was reported by us for PF2/6 in MCH solutions. ${ }^{27}$ However, in that case, we found that the decays were fitted by sums of two exponentials and that the importance of the rise time at longer wavelengths was larger.

When the $437-438 \mathrm{~nm}$ peak is excited and the fluorescence decay collected at the second vibronic transition $(468 \mathrm{~nm})$, to avoid contamination by scattered light, double-exponential decays are found, but the decay times are shorter (130 and 270 ps), as shown in Figure $3 \mathrm{~b}$. With this excitation wavelength, we do not detect either the 340 ps component or the rise time.

3.2. Temperature Dependence of PFO Absorption and Emission Spectra in MCH Solution. Figure 4a) shows the temperature dependence $(290-230 \mathrm{~K})$ of the absorption spectrum of PFO in MCH solution, prepared at $363 \mathrm{~K}$ and then left to equilibrate in the dark at room temperature.

No red-shifted peak is observed at $290 \mathrm{~K}$. Decreasing the temperature solution down to $230 \mathrm{~K}$ (Figure 4a) induces a strong increase of the $437-438 \mathrm{~nm}$ peak at the expense of the main absorption band at $384 \mathrm{~nm}$. Note that the spectra were taken at $5 \mathrm{~K}$ intervals, waiting at each temperature until no further changes in the absorption spectrum were observed (ca. 3-4 h).
Upon further cooling from $230 \mathrm{~K}$ down to $170 \mathrm{~K}$, no changes were observed in the absorption spectrum. An isosbestic point is observed at $399 \mathrm{~nm}$, indicating the presence of two absorbing entities at equilibrium. The difference spectrum for data at temperatures of 290 and $230 \mathrm{~K}$ is given in Figure $4 \mathrm{~b}$ and shows the $437 \mathrm{~nm}$ peak and the $0-1$ vibronic at about $409 \mathrm{~nm}$. The appearance of negative values at shorter wavelengths (below $\sim 400 \mathrm{~nm}$ ) is due to the reduction of the main absorption peak intensity.

Absorption spectra of a $\mathrm{PFO} / \mathrm{MCH}$ solution, prepared under the same conditions with an 8-fold higher PFO concentration $(23 \mu \mathrm{g} / \mathrm{mL})$, recorded in the same temperature range, show clear signs of precipitation when the temperature decreases below $270 \mathrm{~K}$. Consequently, the isosbestic wavelength is lost below this temperature. However, at identical temperatures, the spectra are similar to those of the 8-fold more diluted solution (Figure 4a). This can be better appreciated when the spectra below 270 $\mathrm{K}$ are corrected for precipitation, by normalization at the isosbestic wavelength (399 nm), as shown in Figure 4c.

A strong hysteresis effect is observed in both solutions. If, after being at low temperature for several hours, the solution is warmed, the red-shifted peak only disappears if, independently of the concentration, the solution is heated to $363 \mathrm{~K}$.

All these effects are absent in the absorption spectra of the PF2/6 solution in MCH (Figure 4d), where, upon cooling, only a red shift of the normal absorption band is observed.

Figure 5 shows fluorescence spectra of PFO in $\mathrm{MCH}(3 \mu \mathrm{g}$ / $\mathrm{mL}$, prepared at $363 \mathrm{~K}$, with no $438 \mathrm{~nm}$ absorption peak at room temperature), recorded upon excitation at $380 \mathrm{~nm}$, as a function of temperature. The major effect of cooling is an almost complete quenching of the normal emission at about $413 \mathrm{~nm}$ $(3.00 \mathrm{eV})$, accompanied by a strong intensity increase of the emission peak at about $440 \mathrm{~nm}(2.82 \mathrm{eV})$. Below $230 \mathrm{~K}$, the normal emission has only residual intensity. Note also the very well-defined vibronic progression $(0.17 \mathrm{eV})$ of the new emission $(440 \mathrm{~nm})$, below $230 \mathrm{~K}$, resulting from the narrowing of the vibronic peaks.

3.3. Time Dependence of PFO Absorption Spectra in MCH Solution. The development of the absorption peak at 437 $\mathrm{nm}$ was followed, as a function of time, at $260 \mathrm{~K}$. A PFO$\mathrm{MCH}$ solution $(4 \mu \mathrm{g} / \mathrm{mL})$, prepared at $363 \mathrm{~K}$ (therefore without the $437 \mathrm{~nm}$ absorption peak at room temperature), was placed in a cryostat stabilized at $260 \mathrm{~K}$, and the absorption at $437 \mathrm{~nm}$ followed as a function of time $(\mathrm{OD}(t))$. The results are shown in Figure 6. Note the fast development of the absorption in the first $2000 \mathrm{~s}$, followed by a much slower growing. The initial, apparently sigmoidal, part of the plot may be associated with slow thermal equilibration on cooling.

In a different experiment, a $1 \mu \mathrm{g} / \mathrm{mL}$ solutions of $\mathrm{PFO}$ in $\mathrm{MCH}$ with no peak at room temperature were placed in a fridge at ca. $243 \mathrm{~K}$ for $10 \mathrm{~min}$ and then warmed to room temperature. The absorption spectrum exhibits the $437 \mathrm{~nm}$ peak. Filtration of the solution through a $0.22 \mu \mathrm{m}$ membrane removes a small amount of material, as evidenced by a small reduction of the absorption, but the $437 \mathrm{~nm}$ peak is still clearly visible in the filtrate, with nearly the same intensity. If the cooled, unfiltered solution is left standing in the dark for about $24 \mathrm{~h}$ at room temperature, no clear changes are noticed in the absorption spectrum. However, upon filtration of this solution with the same type of $0.22 \mu \mathrm{m}$ membranes, the $437 \mathrm{~nm}$ peak practically disappears from the filtrate's absorption spectrum (see Figure 7). The difference spectrum (before and after filtration) is very similar to the absorption spectrum of the cooled solutions (below $230 \mathrm{~K}$ ) (see Figure 4a). 

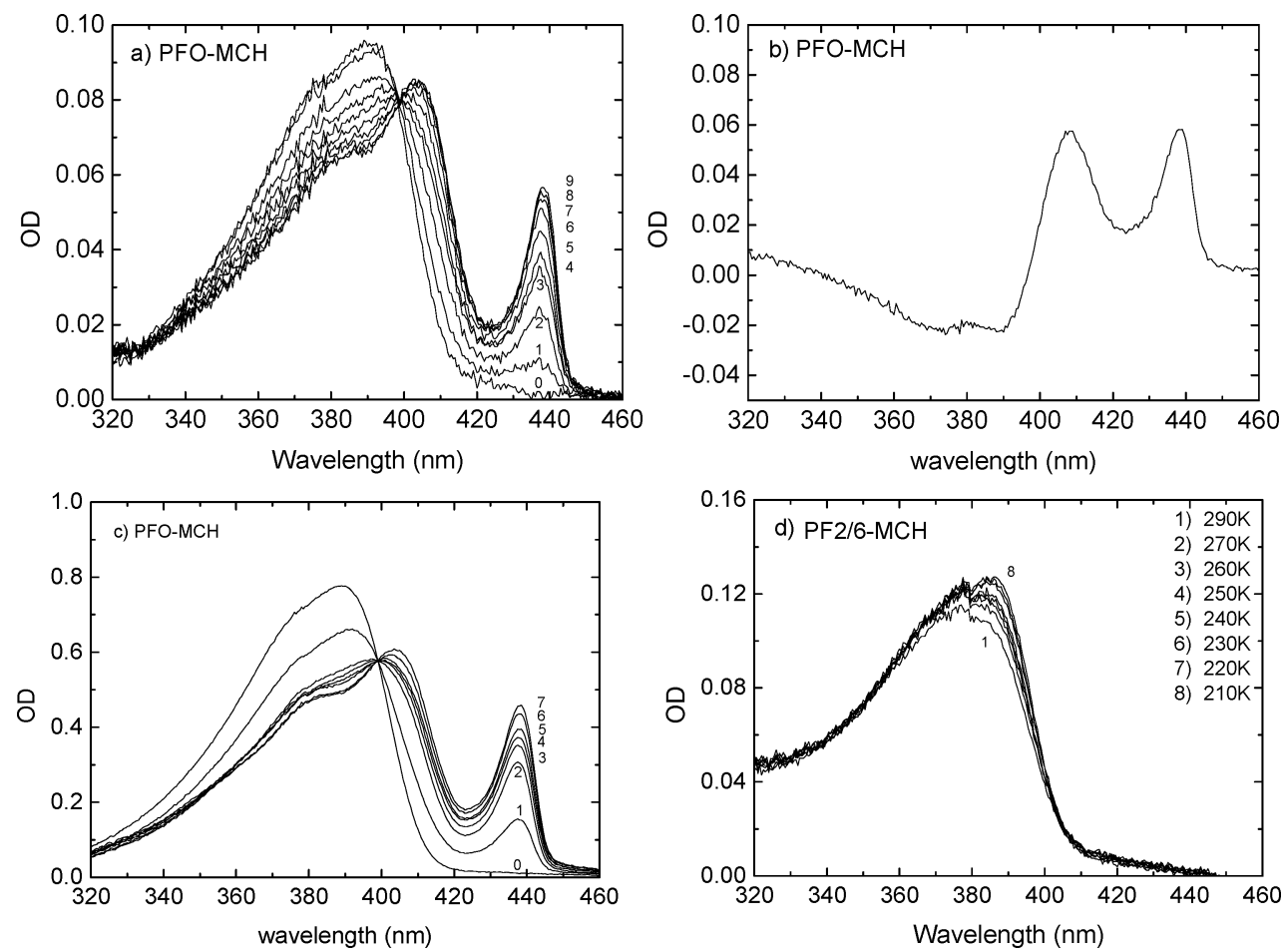

Figure 4. (a) Absorption spectra of PFO in MCH (3 $\mu \mathrm{g} / \mathrm{mL}$ ) at (0) 290, (1) 270, (2) 265, (3) 260, (4) 255, (5) 250, (5) 245, (6) 240, (7) 235, and (8) $230 \mathrm{~K}$. Note the isosbestic wavelength at $399 \mathrm{~nm}$. (b) Difference absorption spectrum obtained by subtracting the absorption spectrum of the $3 \mu \mathrm{g} / \mathrm{mL}$ PFO dilute solution in MCH at 230 and $290 \mathrm{~K}$. (c) Absorption spectra of PFO in MCH (23 $\mu \mathrm{g} / \mathrm{mL})$ at (0) 290, (1) 270, (2) 260, (3) 255, (4) 250, (5) 240, (6) 230, and (7) $220 \mathrm{~K}$. The spectra were corrected for precipitation by normalization at the isosbestic point determined in the dilute solution, free of precipitation effect. (d) Absorption spectra of PF2/6 in $\mathrm{MCH}(4 \mu \mathrm{g} / \mathrm{mL})$ recorded at various temperatures.

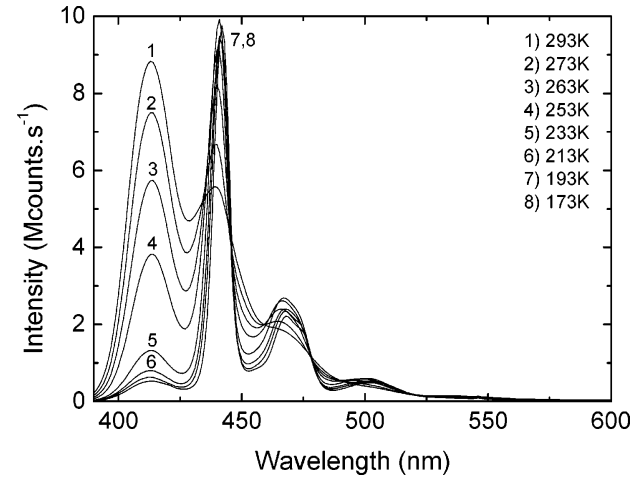

Figure 5. Emission spectra of PFO in $\mathrm{MCH}(3 \mu \mathrm{g} / \mathrm{mL})$ solution as a function of temperature, obtained upon excitation at $380 \mathrm{~nm}$. At room temperature, the spectrum is that of the normal PFO chain conformation, and below $233 \mathrm{~K}$, it is mostly that of the $\beta$-phase.

Finally, if the starting solution (with no $438 \mathrm{~nm}$ peak at room temperature) is placed in the fridge at $243 \mathrm{~K}$ for about $17 \mathrm{~h}$, we then find that its filtration through the $0.22 \mu \mathrm{m}$ membrane removes the material responsible for the $437 \mathrm{~nm}$ peak, as this is almost completely suppressed from the absorption spectrum of the filtrate, along with a strong reduction of the total absorption.

\section{Discussion}

4.1. Optical Properties at Room Temperature. The presence of the 437-438 nm absorption peak in "solutions" of PFO in various solvents at room temperature is due to an incomplete dissolution process, as demonstrated by the filtration experiments. The chromophoric entity responsible for this peak is, therefore, present in the solid state (undissolved material). Its formation is induced by the precipitation of the polymer upon addition of methanol to toluene or xylene PFO solutions (a procedure typically used in the polymer purification) or simply

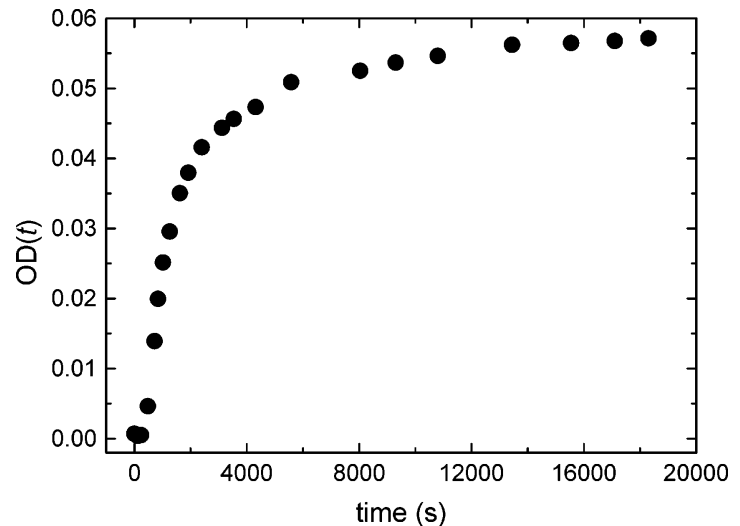

Figure 6. Plot of the optical density of $\mathrm{PFO}$ in $\mathrm{MCH}$ at $437 \mathrm{~nm}$, as a function of time $\mathrm{OD}(t)$, after a temperature drop from 290 to $260 \mathrm{~K}$.

by solvent removal under reduced pressure. On the basis of the emission spectrum obtained upon excitation at the red-shifted absorption peak of PFO in MCH (Figure 1) and on the difference absorption spectrum shown in Figure 4b, we conclude that the PFO state responsible for the red-shifted absorption peak at $437-438 \mathrm{~nm}$ in "solution", and which is trapped in aggregates (as proven by its removal upon filtration), corresponds to the previously identified $\beta$-phase in PFO films ${ }^{13}$ and is attributed to $\mathrm{PFO}$ chain segments in a $\beta$-conformation. ${ }^{17}$ The emission vibronic peaks identified in Figure 1 at 2.82, 2.65, and $2.48 \mathrm{eV}$ match the values of $2.81,2.65$, and $2.49 \mathrm{eV}$ of the $\beta$-phase emission spectrum in PFO films at room temperature. ${ }^{13}$

The similarity between the fluorescence spectrum of $\mathrm{PFO} /$ $\mathrm{MCH}$ solutions obtained upon excitation at $438 \mathrm{~nm}$ and that of the nearly planar ladder-type polymer MeLPPP, where fluorescence originates from an isolated chain, is in agreement with the PFO emission resulting from PFO chain segments with a more planar $(\beta-)$ conformation. The nearly zero $(\approx 10 \mathrm{meV})$ 


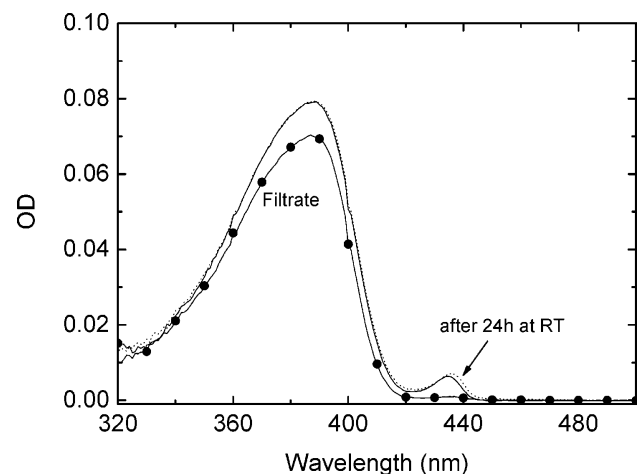

Figure 7. Absorbance of a $1 \mu \mathrm{g} / \mathrm{mL}$ solution of PFO cooled to $243 \mathrm{~K}$ for $10 \mathrm{~min}$ and then warmed to room temperature (full line); after a 24 $\mathrm{h}$ resting period at room temperature (dashed line) and after filtration through a $0.22 \mu \mathrm{m}$ membrane (dots).

Stokes shift between absorption and emission spectra of the PFO $\beta$-conformation, and the high vibronic resolution of the emission spectrum obtained with excitation at $438 \mathrm{~nm}$, show that the conformations of the ground and of the lowest energy excited states are very similar.

The steady-state anisotropy of a fluorophore $\bar{r}$ is given by eq 1 , where $\tau_{i}$ and $a_{i}$ are the decay times and preexponential coefficients of the anisotropy decay, respectively, and $\tau$ is the fluorescence lifetime of the fluorophore. ${ }^{28}$

$$
\bar{r}=r_{0} \sum_{i} \frac{a_{i} \tau_{i}}{\tau_{i}+\tau}
$$

The anisotropy value at time zero, $r_{0}$, is proportional to the mean value of $\cos ^{2} \phi$, where $\phi$ is the angle between the absorption and the emission transition dipole moments (eq 2), and has a maximum theoretical value $r_{0}=0.4 .{ }^{29}$ Experimentally, $r_{0}$ is found in the range $0.32-0.39$ (limiting anisotropy value). ${ }^{28}$

$$
r_{0}=\frac{\overline{3 \cos ^{2} \phi}-1}{5}
$$

In polymers, the anisotropy decay $r(t)$ can be described by a sum of exponentials with decay times $\tau_{i}$ that are associated with rotational motions of the entire polymer chain, torsion motions of the fluorophores around the polymer backbone, and other processes, such as energy migration along the polymer backbone.

For polymers with short-lived fluorophores, as is the case of PFO ( $\tau=370 \mathrm{ps})$, the anisotropy decay due to rotational motion of the entire polymer chains in solution can be neglected $\left(\tau_{i}\right.$ (entire polymer $\left.) \gg \tau\right)$; i.e., only torsion motions of the fluorophores around the polymer backbone and energy transfer from shorter to longer conjugated segments with different orientation of the emission transition dipole moment can contribute to the decrease of the steady-state anisotropy value.

The increase on the steady-state anisotropy value $\bar{r}$ from the PFO absorption maximum at $384 \mathrm{~nm}(\bar{r}=0.11)$ to the red edge at $406 \mathrm{~nm}(\bar{r}=0.16$, Figure 2$)$ suggests a decrease in the torsional degrees of freedom for the more planar fluorophores (which absorb at longer wavelengths) and also reflects the energy distribution of the conjugated segments, as at longer wavelengths there are less energy acceptors for a given excitation. Detailed evidence in support of this scenario was obtained in fluorescence anisotropy studies of PF2/6 in $\mathrm{MCH}$ solution (data not shown). The anisotropy value obtained with excitation at the blue region of the absorption spectrum is temperature independent, but if the excitation occurs on the red side of the absorption spectrum, the anisotropy is temperature dependent and the extrapolation to $77 \mathrm{~K}$ gives the anisotropy value predicted at time zero (eq 2), when the transition dipoles for absorption and emission are collinear.

As shown in Figure 2c, the steady-state fluorescence anisotropy obtained upon excitation at the $437 \mathrm{~nm}$ peak $(\bar{r}=0.35)$ is within the range of the experimental values of the limiting anisotropy value, $r_{0}(0.32-0.39)$. This means there is no anisotropy loss, which can only be explained if the chain segments (fluorophores) do not change orientation during their lifetime and no energy transfer occurs in the domains containing the PFO $\beta$-conformation.

Fluorescence decays of PFO (Figure 3) provide further evidence for large conjugation lengths in the $\beta$-conformation. Anémian et al..$^{30}$ have shown that the fluorescence lifetime of fluorene oligomers is strongly dependent on the number of monomer units. The shorter the oligomer, the longer the lifetime; i.e., the lifetime changes from $\tau_{\mathrm{F}}=1 \mathrm{~ns}$, for the fluorene dimer, to $\tau_{\mathrm{F}}=600 \mathrm{ps}$, for the hexamer.

The fluorescence decay of the $\beta$-conformation, obtained with excitation at the $437 \mathrm{~nm}$ peak and collected at the second vibronic $(468 \mathrm{~nm})$, is double exponential with decay times 130 and 270 ps (Figure 3b) which are shorter than the 340 ps decay time found for the normal emission of PFO in $\mathrm{MCH}$ (Figure 3a). Double-exponential decays have also been found by us with MeLPPP in MCH solution, when the emission was collected at the second vibronic transition $\left(\tau_{1}=140 \mathrm{ps}\right.$ and $\left.\tau_{2}=300 \mathrm{ps}\right)$. On the basis of the correlation reported by Anémian et al., ${ }^{30}$ and taking also into account the fluorescence decay kinetics of MeLPPP in solution, we conclude that the $\beta$-conformation emission, characterized by shorter time constants, arises from chain domains with longer conjugation length than those existing in the PFO chains in the room-temperature disordered conformation. This result is, again, in agreement with the results obtained by Chunwaschirasiri et al. ${ }^{17}$

4.2. Temperature Dependence of Absorption and Emission Spectra in MCH Solution. The temperature dependence of the absorption spectra of dilute solutions of PFO in $\mathrm{MCH}$ (OD < 0.1 at $380 \mathrm{~nm}$ ), in the $173-363 \mathrm{~K}$ temperature range, shows that the formation of the PFO $\beta$-conformation in dilute solution is a reversible process with strong hysteresis. When cooling from $363 \mathrm{~K}$, no $\beta$-conformation peak is observed down to $290 \mathrm{~K}$ independently of the polymer concentration. Below this temperature $(270 \mathrm{~K})$ the red-shifted absorption peak starts to be observed, whose intensity increases upon further cooling. This variation is also accompanied by a red shift of the main absorption band (see Figure 4a). Below $230 \mathrm{~K}$ no further changes on the absorption spectrum were observed, which means that no more $\beta$-conformation domains are formed. This absorption spectrum is different from the absorption spectrum of MeLPPP (inset of Figure 1). Specifically, it shows, in addition to the 437-439 $\mathrm{nm} 0-0$ vibronic transition, a band with broad peaks at 384 and $403 \mathrm{~nm}$, which is not present in absorption spectrum of MeLPPP. The shape of this broad band, in turn, resembles the shape of the absorption spectrum of PF2/6 at low temperature, with peaks at 376 and $388 \mathrm{~nm}$ (Figure 4d). ${ }^{26}$ Fluorescence spectra provide similar information. At room temperature, the spectrum is that of the normal PFO chain conformation, and below $230 \mathrm{~K}$ it is essentially that of the $\beta$-conformation, independent from excitation wavelength (Figure 5 ), with a minor or residual contribution from the normal emission spectrum. 

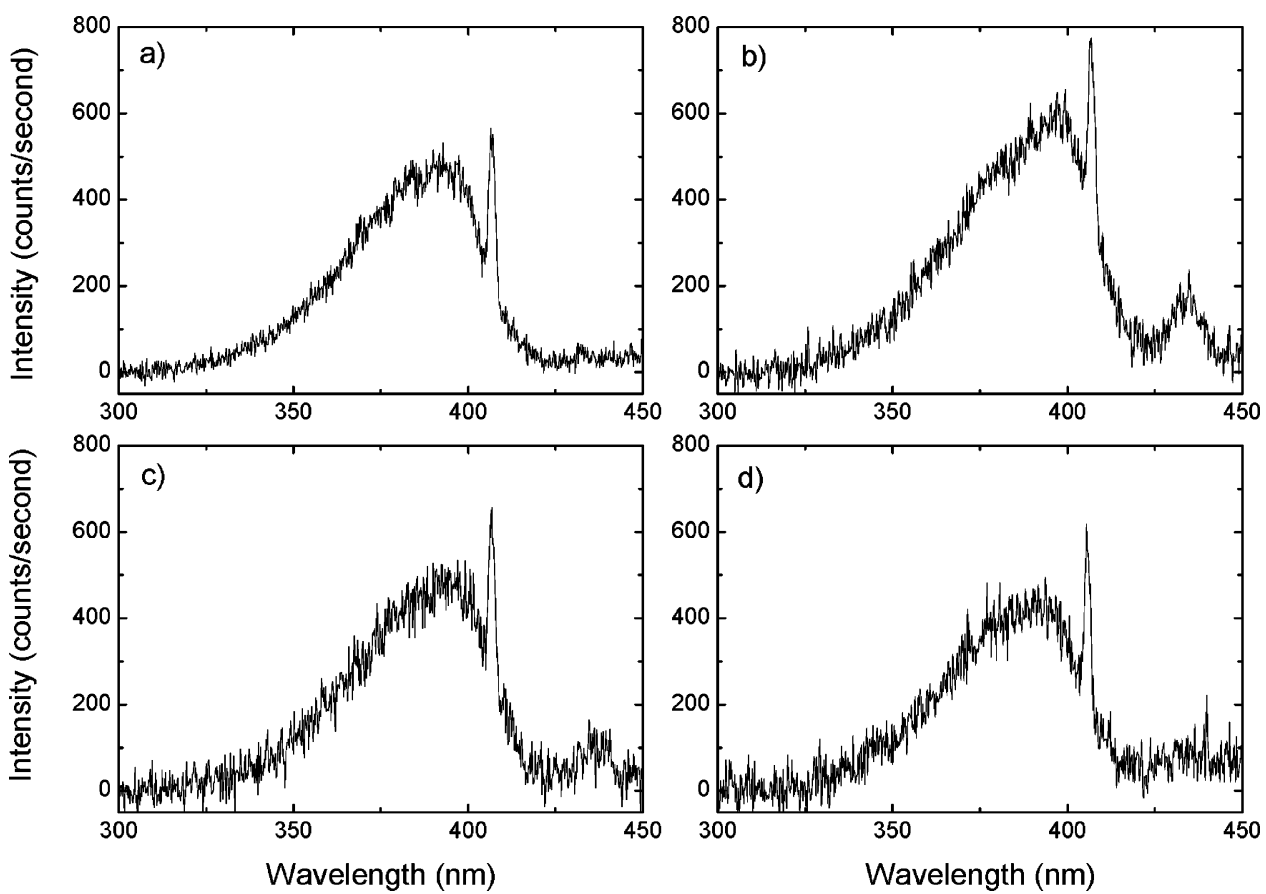

Figure 8. Excitation spectra of a PFO-MCH solution with OD $<0.004$, emission collected at $460 \mathrm{~nm}$ : (a) $T=295 \mathrm{~K}$, before the temperature jump to $270 \mathrm{~K}$; (b) $T=270 \mathrm{~K}, 2400 \mathrm{~s}$ after the temperature jump from $295 \mathrm{~K}$; (c) $T=295 \mathrm{~K}, 7200 \mathrm{~s}$ after coming back from $270 \mathrm{~K}$; and (d) $T=295 \mathrm{~K}, 79200 \mathrm{~s}$ after coming back from $270 \mathrm{~K}$.

All the foregoing suggest that below $230 \mathrm{~K}$ the $\mathrm{PFO}$ absorption and emission spectra correspond to two different conformations: $\alpha$ and $\beta$. We, therefore, propose that two different conformational domains coexist in the PFO chains: (i) highly ordered $\beta$-conformation regions ( $\beta$-phase), in which the chromophores assume an ordered and MeLPPP-like extended planar conformation, and (ii) low-order regions $(\alpha)$, similar to the conformation of PF2/6. The observation of an efficient energy transfer process from $\alpha$ to $\beta$ domains in dilute solutions, as indicated by the almost complete quenching of the emission at $413 \mathrm{~nm}$ (Figure 5), indicates that these two domains are very close (within the same chain). In fact, the observation that below $230 \mathrm{~K}$ the fluorescence emission is (almost) exclusively that of the $\beta$-conformation, independent of the excitation wavelength, implies that the more ordered regions act as efficient energy traps, quenching the fluorescence coming from the disordered regions. Such efficiency of energy migration $\left(k_{\mathrm{ET}} \gg 1 / 340 \mathrm{ps}^{-1}\right)$ in dilute solution also suggests that no chains free of $\beta$-conformation domains are present in the system below $230 \mathrm{~K}$.

The transition from the disordered conformation of PFO chains in dilute $\mathrm{MCH}$ solutions at room temperature, to a state where ordered $\beta$-conformation domains coexist with disordered domains in the same chain, upon cooling, is accompanied/ followed by an aggregation process, which may lead to the formation of nanoaggregates, as indicated by the filtration experiments performed in $1 \mu \mathrm{g} / \mathrm{mL}$ solutions of PFO in $\mathrm{MCH}$ cooled in a fridge at ca. $243 \mathrm{~K}$ (Figure 7). These studies suggest that, in fact, two processes occur during the cooling process: an intramolecular process, which leads to the conversion of parts of the PFO chain into the ordered $\beta$-conformation, and, at longer times, an aggregation process.

Additional experimental evidence for the reversibility of the first essentially intramolecular step can be obtained from the formation of $\beta$-phase domains in an extremely dilute solution. In fact, the occurrence of successive aggregation processes should be dependent on the solution concentration, and decreasing the possibility of successive aggregation steps by dilution, the reversibility of $\beta$-phase formation at early times can be followed, for example at $295 \mathrm{~K}$, and after returning from a temperature jump to $270 \mathrm{~K}$.

A PFO solution with $\mathrm{OD}=0.37$ in $\mathrm{MCH}$ and with no $\beta$-phase domains was diluted by a factor of 100 (to OD $<0.004$ ) and heated to $368 \mathrm{~K}$ to guarantee that no $\beta$-phase domains were present. Using fluorescence instead of absorption, which is much more sensitive, the disappearance of the "absorption" peak at $437 \mathrm{~nm}$ is followed at $295 \mathrm{~K}$ after being at $270 \mathrm{~K}$ for $2400 \mathrm{~s}$. Figure 8a shows the PFO/MCH excitation spectrum at $295 \mathrm{~K}$ before the temperature jump to $270 \mathrm{~K}$; the peak at $437 \mathrm{~nm}$ characteristic of $\beta$ domains is not present. Figure $8 \mathrm{~b}$ shows the excitation spectrum of the same solution after a temperature jump to $270 \mathrm{~K}$ for $2400 \mathrm{~s}$; note the appearance of the red-shifted peak. Figure $8 \mathrm{c}$ shows the excitation spectrum of the same solution after $7200 \mathrm{~s}$ of returning back to $295 \mathrm{~K}$; the decrease on the intensity of the red-shifted peak is already evident, suggesting that in fact the formation of $\beta$ domains is controlled by a first reversible step. Finally, Figure $8 \mathrm{~d}$ shows the excitation spectrum of the same solution after $79200 \mathrm{~s}$ after returning to $295 \mathrm{~K}$; the $437 \mathrm{~nm}$ absorbance is no longer present.

It is now necessary to address the nature and degree of crystallinity of these aggregates. The fact that they grow and can be filtered out of solution indicates they are relatively large. However, on the basis of recent SANS investigations, it can be concluded that the PFO/MCH system contains sheetlike objects whose thickness is only $2-3 \mathrm{~nm}$, corresponding to the thickness of $2-3$ stiff polymers. ${ }^{31}$ Such a structure, lacking any threedimensional order, cannot strictly be regarded as a true crystal but is closer to the anisotropic lamellar structures seen in certain ordered smectic phases. In recent unpublished SANS studies, the $q$ range was extended up to $0.45 \AA^{-1}$, and no interference maximum or "Bragg peak" was observed. Although this does not confirm the lack of crystallinity, since even in the hypothetical case where the sheets were "ordered" along their surface normal the thinness of the sheets would prevent formation of interference maxima, they do support a highly anisotropic structure. We also note that the contrast seen in SANS between 
systems with PFO deuterated on the octyl side chains and deuterated $\mathrm{MCH}$ leads to the same sheet thickness, suggesting that the polymer backbones are distributed within the sheets. As has been discussed by Knaapila et al., ${ }^{32}$ a complete distinction between polyfluorene aggregates, paracrystals, and crystals is delicate in general, since lattice imperfections of the first and second kind dominate in even the best crystal-like material. However, we believe that it is more appropriate to consider the final structure as an ordered lamellar phase rather than as a true crystal, and therefore we will still refer to them in an oversimplified way as aggregates.

4.3. Kinetics of the $\boldsymbol{\beta}$-Phase Formation. The dynamic formation of the $\beta$-phase, assessed by the absorbance value at $437 \mathrm{~nm}(\mathrm{OD}(t)$, see Figure 6), combines the formation of $\beta$-conformation domains and their aggregation. Although these processes are interrelated and the equilibria are coupled, an approximate separation is possible because they occur on very different time scales. While, as discussed above, we do not believe a discussion of the domains in terms of crystallinity is appropriate, the kinetics of phase transformation does show some similarities to that of crystallization. ${ }^{33}$

To model/fit the experimental data and obtain kinetic and thermodynamic data, we propose a mechanism in which a first step describes the formation of $\beta$-conformation domains (represented by $\beta_{1}$ ) from random conformation domains (represented by $\alpha$ ) (eq 3 ).

$$
\alpha \underset{k_{1}}{\stackrel{k_{-1}}{\rightleftarrows}} \beta_{1}
$$

We are assuming that the random conformation domains contain, on average, the same number of monomers as the $\beta$-conformation ones. That is, we assume we have a 1:1 transformation from $\alpha$ to $\beta$. This allows us to establish a simple relation between the concentrations of $\alpha$ - and $\beta$-domains. This assumption could also be rationalized as if there was the formation of a single $\beta$-domain per PFO chain, although this is an oversimplification, since physically, the occurrence of domains per chain could be randomly distributed, such that each chain can have both $\alpha$ - and $\beta$-domains, more than one $\beta$-domain, or even no $\beta$-domains at all.

This first step (3), of essentially intramolecular nature, leading to the formation of "individual" $\beta$-conformation domains, is reversible with rate constants $k_{1}$ and $k_{-1}$ for the direct and reverse reactions, respectively.

This first reaction is then followed by an aggregation processes, described by (4):

$$
\beta_{1}+\beta_{k} \underset{k_{\mathrm{diss}}}{\stackrel{k_{\mathrm{agg}}}{\rightleftarrows}} \beta_{k+1}, \quad k \in\{1, \ldots, N-1\}
$$

where $k_{\text {agg }}$ and $k_{\text {diss }}$ are the rate constants for the direct and reverse reactions and $\beta_{k}$ designates an "aggregate" formed by $k$ ordered $(\beta)$ domains. We note that the aggregates will also contain residual $\alpha$-domains coexisting in the same chain with the $\beta$-conformation ones. However, following the $\mathrm{OD}(437 \mathrm{~nm})$ only gives us access to the concentration of $\beta$-conformation domains.

Assuming that at time zero only $\alpha$-conformation domains are present in the system, with an initial concentration $\alpha_{0}>0$, the optical density at $437 \mathrm{~nm}$ becomes proportional to the total concentration of $\beta$-phase in any possible form, i.e., proportional to $\sum_{k=1}^{N} k \beta_{k}(t)$, because $\beta_{1}$ contributes with one domain, $\beta_{2}$ with two domains, $\beta_{3}$ with three domains, and so on. Under this assumption, the time evolution of the $\beta$-domains concentra-

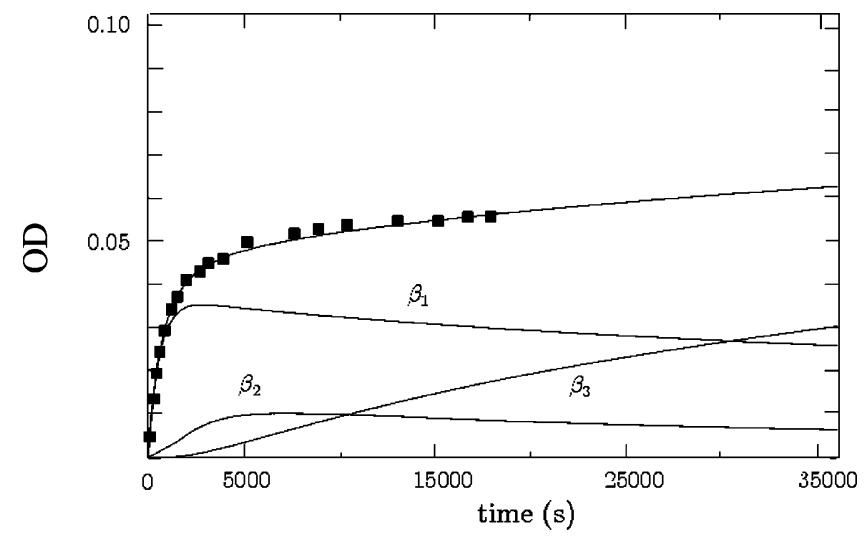

Figure 9. Fitting to a mechanism involving a final irreversible aggregation process with $N=3: k_{1}=5.9 \times 10^{-4} \mathrm{~s}^{-1} ; k_{-1}=9 \times 10^{-4}$ $\mathrm{s}^{-1} ; k_{\text {agg }}=2.3 \times 10^{-3} \mathrm{M}^{-1} \mathrm{~s}^{-1} ; k_{\text {diss }}=4.4 \times 10^{-4} \mathrm{~s}^{-1}$.

tion (which we designate as $\beta_{i}$ ) and of $\alpha$-domains $(\alpha)$ are given by a set of differential equations (5), which have to be solved by numerical methods.

$$
\begin{gathered}
\frac{\mathrm{d} \alpha}{\mathrm{d} t}=-\left(k_{1} \alpha-k_{-1} \beta_{1}\right) \\
\frac{\mathrm{d} \beta_{1}}{\mathrm{~d} t}=\left(k_{1} \alpha-k_{-1} \beta_{1}\right)-J_{1}(\beta)-\sum_{k=1}^{N-1} J_{k}(\beta) \\
\frac{\mathrm{d} \beta_{k}}{\mathrm{~d} t}=J_{k-1}(\beta)-J_{k}(\beta), \quad 2 \leq k \leq N \\
\frac{\mathrm{d} \beta_{N}}{\mathrm{~d} t}=J_{N-1}(\beta)
\end{gathered}
$$

with $J_{k}(\beta)=k_{\mathrm{agg}} \beta_{1} \beta_{k}-k_{\text {diss }} \beta_{k+1}$.

In Figure 9, we compare the fit of the experimental data (absorbance at $437 \mathrm{~nm}$ as a function of time at $260 \mathrm{~K}$ ) to this model using $N=3$. The fitting parameters are $k_{1}=5.9 \times 10^{-4}$ $\mathrm{s}^{-1}, k_{-1}=9 \times 10^{-4} \mathrm{~s}^{-1}, k_{\mathrm{agg}}=2.3 \times 10^{-3} \mathrm{M}^{-1} \mathrm{~s}^{-1}$, and $k_{\text {diss }}=4.4 \times 10^{-4} \mathrm{~s}^{-1}$. Consistent with the observed hysteresis effect upon cooling and warming cycling, we considered that the last step of aggregation becomes irreversible. Under this assumption, when $t \rightarrow \infty$, all the mass in the system will be in the $\beta_{N}$ form so $\mathrm{OD}(\infty)$ will be proportional to $N \beta_{N}$. However, given the fact that the magnitude of the rate constants involved is so small (on the order of $10^{-4}$ ), we conclude that, for every reasonable experimental time window, the system is far from that final solution. In fact, we find that for $N=3$ (see Figure 9) the optical density of $\beta_{3}, \mathrm{OD}\left(\beta_{3}\right)$, after $10 \mathrm{~h}$ is $50 \%$ of the total value. For $N=50, \operatorname{OD}\left(\beta_{50}\right)$ after 2 days will be $25 \%$ of the total OD.

4.4. Thermodynamics of the $\boldsymbol{\beta}$-Phase Formation. At equilibrium (when $t \rightarrow \infty$ ), the vector $\left(\alpha^{\infty}, \beta_{1}^{\infty}, \ldots, \beta_{p}^{\infty}, \ldots\right)$ describes the solution of reactions 3 and 4 . The components of this vector are $\beta_{1}^{\infty}=K_{1} \alpha^{\infty}$ and $\beta_{p}^{\infty}=K_{1} K_{2} \alpha^{\infty} \beta_{p-1}^{\infty}$, being $K_{1}=$ $k_{1} / k_{-1}$ and $K_{2}=k_{\text {agg }} / k_{\text {diss }}$ the equilibrium constants for reactions 3 and 4 , respectively. If we consider an infinite set of reactions (3) and (4), that is, considering $N=\infty$ in (5), then we obtain

$$
\beta_{p}^{\infty}=\frac{1}{K_{2}}\left(K_{1} K_{2} \alpha^{\infty}\right)^{p}, \quad p \geq 1
$$

Inserting this equation into eq 7 describing the mass conservation

$$
\alpha^{\infty}+\sum_{p=1}^{\infty} p \beta_{p}^{\infty}=\alpha_{0}
$$


gives eq 8:

$$
\alpha^{\infty}+\frac{K_{1} \alpha^{\infty}}{\left(1-K_{1} K_{2} \alpha^{\infty}\right)^{2}}=\alpha_{0}
$$

If $y$ is the fraction of the initial $\alpha$-domains converted into $\beta$-conformation domains in the different $\beta_{\mathrm{p}}$ aggregates, then $\alpha^{\infty}=(1-y) \alpha_{0}$, so eq 8 can be rewritten as

$$
\frac{K_{1}}{\left(1-K_{1} K_{2} \alpha^{\infty}\right)^{2}}=\frac{y}{1-y}
$$

Note that $K_{1} K_{2} \alpha^{\infty}=K_{1} K_{2}(1-y) \alpha_{0}<K_{1} K_{2} \alpha_{0}$. For the PFO/ $\mathrm{MCH}$ solution used in this study, with total PFO concentration of $4 \mu \mathrm{g} / \mathrm{mL}$, the limiting value of $K_{1} K_{2} \alpha^{\infty}$ (maximum) will be that corresponding to $10^{-5} \mathrm{M}$ of PFO monomer concentration, as the average number of monomers per $\beta$-domain is certainly higher than one. From the analysis of the kinetic data, above, we obtain $K_{1}(260 \mathrm{~K}) \approx 1$ and $K_{2}(260 \mathrm{~K}) \approx 10$, so at this temperature $K_{1} K_{2} \alpha_{0}<10^{-4}$. Equation 9 can now be simplified to

$$
K_{1}=\frac{y}{1-y}
$$

To estimate the order of magnitude of the thermodynamic parameters associated with the change of conformation, we make a further assumption in relation to reaction 3. Namely, we consider the case where we have the formation of a single $\beta$-domain per PFO chain. Within this approximation, the fraction of material converted into $\beta$-conformation, and incorporated into the different $\beta_{\mathrm{p}}$ aggregates, can be estimated from the study of the conversion of disordered PFO chains into $\beta$-conformation domains as a function of the temperature (Figure $4 \mathrm{a}, \mathrm{c}$ ). We observed that, below $230 \mathrm{~K}$, the absorption spectrum does not change upon further cooling, indicating that we have obtained the maximum possible conversion to the ordered conformation, still leaving some disordered, $\alpha$-conformation domains. So, the maximum conversion corresponds to the intensity of the 438 nm peak at $230 \mathrm{~K}\left(A_{438}^{0}\right)$, which corresponds to $y=1$ in eq 10 . At $230 \mathrm{~K}$ (and below) we have already all chains with a $\beta$-conformation domain. The molar fraction of chains with $\beta$-phase domains ( $y$ ) can be determined from the absorption spectra of PFO/MCH solutions as a function of temperature. Below $230 \mathrm{~K}$, the absorbance at $438 \mathrm{~nm}$ and, in fact, the whole absorption spectrum remains unchanged despite the strong temperature dependence of the transition.

From data presented in Figure $4 \mathrm{a}, \mathrm{c}$ the molar fraction of $\beta$-phase domains, defined by the ratio between the absorbance at $437-438 \mathrm{~nm}\left(A_{438}\right)$ at a particular temperature and the absorbance at the same wavelength at $T \leq 230 \mathrm{~K}\left(A_{438}^{0}\right)$ (where $y=1$ ) can be followed as a function of temperature.

$$
y=A_{438} / A_{438}^{0}
$$

Figure 10a is a plot of $y$ vs temperature for two different concentrations, 3 and $23 \mu \mathrm{g} / \mathrm{mL}$. $y$ values were obtained using eq 11 with data in Figure $4 \mathrm{a}$ for the dilute solution and similar data (after correcting for precipitation by normalization at the isosbestic point determined in the dilute, precipitation-free, solution) for the concentrated solution (Figure 4c). Note that, though we do not know the exact concentration of the material remaining in solution, at low temperatures, for the $23 \mu \mathrm{g} / \mathrm{mL}$ solution, the $y$ values are similar for both solutions. Combining
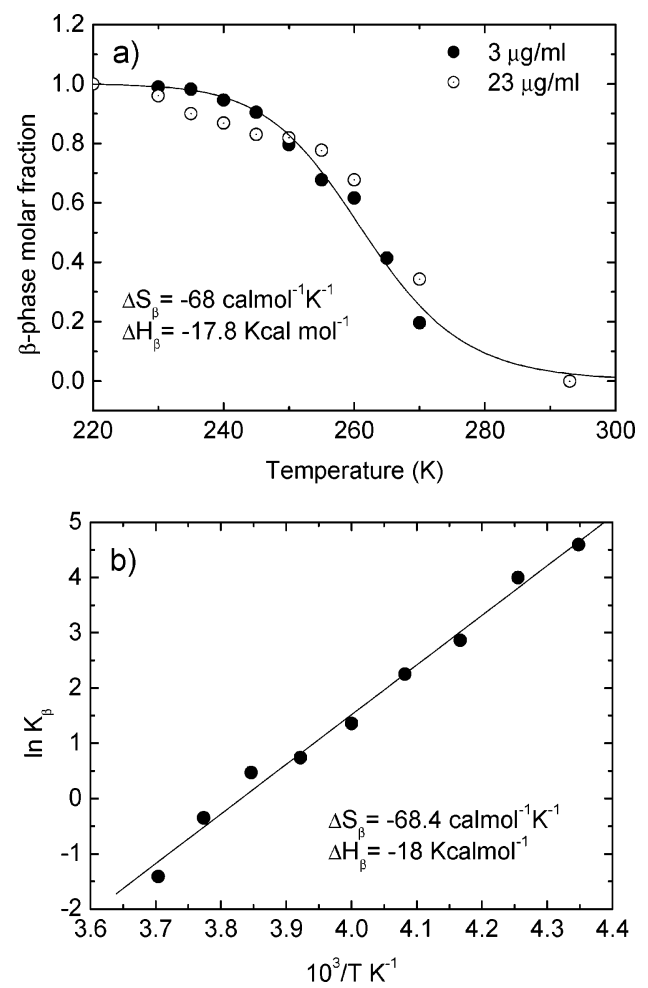

Figure 10. (a) Plot of the mole fraction of $\beta$-phase $(y)$ as a function of temperature for two different concentrations ( 3 and $23 \mu \mathrm{g} / \mathrm{mL}$ ). (b) van't Hoff plot of the transition equilibrium constant $\left(K_{\beta}\right)$ for the more diluted sample.

this observation with the above-mentioned results regarding the evidence for aggregation, we conclude that the contribution for the red-shifted absorption peak is mainly intramolecular, the aggregation occurring over longer time scales. Rughooputh, ${ }^{1}$ when studying the thermochromism of poly(3-hexylthiophene) and of two substituted polydiacetylenes, concluded that there was a single-chain mechanism, involving an intrachain collapse of individual polymer chains upon cooling, leading to the coexistence of ordered and disordered regions in a single polymer chain.

In Figure 10b, the van't Hoff plot of the transition equilibrium constant $K_{\beta}$ (eq 12) is shown for the more diluted solution.

$$
K_{\beta}=\frac{y}{1-y}
$$

From the linear analysis of the van't Hoff plot (Figure 10b), values for the standard enthalpy $\Delta H_{\beta}=-18.0 \mathrm{kcal} \mathrm{mol}^{-1}$ $(-0.78 \mathrm{eV})$ and standard entropy $\Delta S_{\beta}=-68.4 \mathrm{cal} \mathrm{mol}^{-1} \mathrm{~K}^{-1}$ of transition were obtained. The nonlinear fit of $y$ (for the 3 $\mu \mathrm{g} / \mathrm{mL}$ solution) as a function of $T$ (see Figure 10a) using $\Delta H_{\beta}$ and $\Delta S_{\beta}$ as fitting parameters in eq 13 provided similar values.

$$
\ln K_{\beta}=\frac{\Delta S_{\beta}}{R}-\frac{\Delta H_{\beta}}{R T}
$$

The values of $\Delta H_{\beta}$ and $\Delta S_{\beta}$ demonstrate that the $\beta$-phase formation is strongly exothermic and involves considerable entropy loss. Three factors can be suggested to be involved in the thermodynamics of formation of the $\beta$-phase: interaction between octyl chains on adjacent monomers, interaction between alkyl chains and fluorene backbones (as suggested by Chunwaschirasiri et al., ref 17), and ordering of the fluorene backbone conformation. Using conformational differences and changes in van der Waals interactions, good estimates can be made of 
the enthalpy change when alkyl chains associate as has been discussed in detail elsewhere. ${ }^{34}$ For the two octyl chains presenting in each PFO unimer, the calculated enthalpy change is $13 \mathrm{kcal} \mathrm{mol}^{-1}$, which is comparable to the value observed experimentally for $\beta$-phase formation, suggesting this may be a major contributing factor. A similar treatment for the entropy change in this transition predicts a value of $38 \mathrm{cal} \mathrm{mol}^{-1} \mathrm{~K}^{-1}$, significantly lower than that observed, showing that this is not the only factor and that either alkyl chain-fluorene interaction or backbone ordering must also contribute. From the above kinetic, thermodynamic, and structural discussion, the formation of the $\beta$-phase domains can then be summarized in two steps: First as a response of changes in the quality of the solvent with temperature, domains with a more planar conformation are formed in the polymer chains; this step is reversible and shows an essentially intramolecular nature. Second, an intermolecular aggregation process, triggered by the adoption of a " $\beta$-phase" conformation, develops to produce low-dimensional polymer sheets.

\section{Concluding Remarks}

The addition of a miscible poor solvent to a solution of a random coil polymer leads, in general, to the collapse of the polymer chains, forming mostly aggregates (and precipitation) or globules. In contrast, when one is dealing with PFO, a "hairyrod" polymer, dissolution in a poor solvent leads to the formation at low temperatures of special conformations where disordered and ordered domains coexist. Small-angle neutron scattering (SANS) studies suggest that these involve sheetlike structures, with characteristic thickness $2-3 \mathrm{~nm} .{ }^{31}$ The same type of nanostructure is thought to be formed upon solvent removal from PFO solutions. The ordered conformation domains exhibit spectral features which are similar to those of the solid-state $\beta$-phase. Furthermore, the same ordered $\beta$-conformation domains are induced in PFO solutions in $\mathrm{MCH}$ upon cooling. Despite the existence of interchain interactions, which lead to aggregation and solution precipitation, and although the nature of the PFO species present in dilute solutions of poor solvents is still an open question, namely the role of interdigitation of the alkyl side chains which is currently under investigation using smallangle neutron scattering, the transition to an ordered conformation, with the concomitant formation of $\beta$-conformation domains, has at early times an essentially intramolecular origin. The formation of nanostructures is an aftermath, as proposed for other conjugated polymers.

Acknowledgment. F. B. Dias acknowledges FCT (Portugal) for a postdoctoral grant (SFRH/BPD/5721/2001), and One North-East, via the Durham county, subregional partnership (Project No. SP/082). We are grateful to POCTI, FCT, FEDER, and the Royal Society for further funding. We thank U. Scherf for providing the PF2/6 and MeLPPP samples and M. Knaapila for the SANS results in PFO/MCH solutions.

\section{Appendix}

The set of differential equations (5) are, essentially, a particular case of the truncated Becker-Döring system. ${ }^{35}$ The existence of solutions to the problems with initial values is trivial by the classic theorem of Picard-Lindelöf. One can also easily verify that the total mass, proportional to $\rho=\alpha+\sum_{k=1}^{N} k \beta_{k}$, is constant because $\mathrm{d} \rho / \mathrm{d} t=0$. This fact, along with the nonnegative solutions, which can be obtained by the method used in ref 35 (Lemma 2.1), allows us to conclude that all nonnegative solutions are defined in $\mathbf{R}$ and they conserve the mass. As we expect that the solutions to the set of differential equations (5) cannot be written in terms of elementary functions, we analyzed the application of this model to describe the experimental data by means of numerical calculations. We assume that at time $t=0$ there is only $\alpha$-conformation domains, with concentration $\alpha_{0}$. The experimentally accessed value, $\operatorname{OD}(438 \mathrm{~nm})$, is proportional to the total concentration of $\beta$-conformation domains, in any form, that is, $\operatorname{OD}(437 \mathrm{~nm}, t)$ is proportional to $\sum_{k=1}^{N} k \beta_{k}(t)$. This quantity is $\alpha_{0}-\alpha(t)$ due to the conservation of mass.

\section{References and Notes}

(1) Rughooputh, S. D. D. V. Synth. Met. 1996, 80, 195.

(2) Bradley, D. D. C.; Grell, M.; Long, X.; Mellor, H.; Grice, A.; Inbasekaran, M.; Woo, E. P. Proc. SPIE 1997, 3145, 254.

(3) Grell, M.; Bradley, D. D. C.; Long, X.; Chamberlain, T.; Inbasekaran, M.; Woo, E. P.; Soliman, M. Acta Polym. 1998, 49, 439.

(4) Blondin, P.; Bouchard, J.; Beaupré, S.; Belletête, M.; Durocher, G.; Leclerc, M. Macromolecules 2000, 33, 5874.

(5) (a) List, E. J. W.; Güntner, R.; Sandiucci de Freitas, P.; Scherf, U. Adv. Mater. 2002, 14, 374. (b) Dias, F. B.; Maiti, M.; Hintschich, S. I.; Monkman, A. P. J. Chem. Phys. 2005, 122, 054904. (c) Sims, M.; Bradley, D. D. C.; Ariu, M.; Koeberg, M.; Asimakis, A.; Grell, M.; Lidzey, D. G. Adv. Funct. Mater. 2004, 14, 765

(6) Teetsov, J. A.; Bout, D. A. V. J. Am. Chem. Soc. 2001, 123, 3605.

(7) Teetsov, J.; Bout, D. A. V. Langmuir 2002, 18, 897.

(8) Grell, M.; Bradley, D. D. C.; Ungar, G.; Hill, J.; Whitehead, K. S. Macromolecules 1999, 32, 5810.

(9) Cadby, A. J.; Lane, P. A.; Wohlgenannt, M.; An, C.; Vardeny, Z. V.; Bradley, D. D. C. Synth. Met. 2000, 111-112, 515.

(10) Teetsov, J.; Fox, M. A. J. Mater. Chem. 1999, 9, 2117.

(11) Cadby, A. J.; Lane, P. A.; Mellor, H.; Martin, S. J.; Grell, M.; Giebler, C.; Bradley, D. D. C.; Wohlgenannt, M.; An, C.; Vardeny, Z. V. Phys. Rev. B 2000, 62, 15604.

(12) Korovyanko, O. J.; Vardeny, Z. V. Chem. Phys. Lett. 2002, 356, 361.

(13) Ariu, M.; Sims, M.; Rahn, M. D.; Hill, J.; Fox, A. M.; Lidzey, D. G.; Oda, M.; Cabanillas-Gonzalez, J.; Bradley, D. D. C. Phys. Rev. B 2003, 67, 195333.

(14) Winokur, M. J.; Slinker, J.; Huber, D. L. Phys. Rev. B 2003, 67, 184106.

(15) Khan, A. L. T.; Sreearunothai, P.; Herz, L. M.; Banach, M. J.; Köhler, A. Phys. Rev. B 2004, 69, 085201.

(16) Scherf, U.; List, E. J. W. Adv. Mater. 2002, 14, 477.

(17) Chunwaschirasiri, W.; Tanto, B.; Huber, D. L.; Winokur, M. J. Phys. Rev. Lett. 2005, 94, 107402.

(18) (a) Ballauff, M. Angew. Chem., Int. Ed. Engl. 1989, 28, 253-267. (b) Wegner, G. Macromol. Chem. Phys. 2003, 204, 347-357. (c) Subotin, A.; Stepanyan, R.; Knaapila, M.; Ikkala, O.; ten Birinke, G. Eur. Phys. J. E 2003, 12, 333-345. (d) Knaapila, M.; Ikkala, O.; Torkkeli, M.; Jokela, K.; Serimaa, R.; Dolbnya, I. P.; Bras, W.; ten Brinke, G.; Horsburgh, L. E.; Palsson, L. O.; Monkman, A. P. Appl. Phys. Lett. 2002, 81, 1489-1491.

(19) Yamamoto, T. Macromol. Rapid Commun. 2002, 23, 583.

(20) Grell, M.; Knoll, W.; Lupo, D.; Meisel, A.; Miteva, T.; Neher, D.; Nothofer, H.-G.; Scherf, U.; Yasuda, A. Adv. Mater. 1999, 11, 671.

(21) Scherf, U.; Müllen, K. Makromol. Chem., Rapid Commun. 1991, 12, 489.

(22) Scherf, U.; Bohnen, A.; Müllen, K. Makromol. Chem., Macromol. Chem. Phys. 1992, 193, 1127.

(23) Monkman, A. P.; Burrows, H. D.; Hamblett, I.; Navaratnam, S.; Scherf, U.; Schmitt, C. Chem. Phys. Lett. 2000, 327, 111.

(24) Lima, J. C.; Abreu, I.; Brouillard, R.; Maçanita, A. L. Chem. Phys. Lett. 1998, 298, 189.

(25) Dias, F. B.; Lima, J. C.; Horta, A.; Pierola, I. F.; Maçanita, A. L. Macromolecules 2002, 35, 7082.

(26) Stricker, G.; Subramaniam, V.; Seidel, C. A. M.; Volkmer, A. J. Phys. Chem. B 1999, 103, 8612 .

(27) Dias, F. B.; Maçanita, A. L.; Melo, J. S.; Burrows, H. D.; Güntner, R.; Scherf, U.; Monkman, A. P. J. Chem. Phys. 2003, 118, 7119.

(28) Valeur, B. Molecular Fluorescence-Principles and Applications; Wiley-VCH: Weinheim, Germany, 2002; Chapter 5.

(29) Steiner, R. In Topics in Fluorescence Spectroscopy; Lakowicz, J. R., Ed.; Plenum Press: New York, 1991; Vol. 2, pp 7, 15.

(30) Anémian, R.; Mulatier, J. C.; Andraud, C.; Stéphan, O.; Vial, J. C. Chem. Commun. 2002, 1608.

(31) Knaapila, M.; Garamus, V. M.; Dias, F. B.; Almásy, L.; Galbrecht, F.; Charas, A.; Morgado, J.; Burrows, H. D.; Scherf, U.; Monkman, A. P. Macromolecules, submitted for publication.

(32) Knaapila, M. Adv. Funct. Mater. 2006, 16, 599. 
(33) (a) Avrami, M. J. Chem. Phys. 1939, 7, 1103. (b) Avrami, M. J. Chem. Phys. 1940, 8, 212. (c) Mandelkern, L.; Quinn, F. A.; Flory, P. J. J. Appl. Phys. 1954, 25, 830. (d) Palberg, T. J. Phys.: Condens. Matter 1999, 11, R323.

(34) (a) Nagle, J. F.; Gujrati, P. D.; Goldstein, M. J. Phys. Chem. 1984 88, 4599. (b) Bazuin, G. C.; Guillon, D.; Skoulios, A.; Amorim da
Costa, A. M.; Burrows, H. D.; Geraldes, C. F. G. C.; Teixeira-Dias, J. J. C.; Blackmore, E.; Tiddy, G. J. T. Liq. Cryst. 1988, 3, 1655.

(35) Ball, J. M.; Carr, J.; Penrose, O. Commun. Math. Phys. 1986, 104, 657-692.

MA0602932 